\title{
Minireview Telomere and telomerase in stem cells
}

\author{
E Hiyama*,I and K Hiyama $^{2}$ \\ 'Division of Life Science Research, Natural Science Center for Basic Research and Development, Hiroshima University, I-2-3, Kasumi, Minami-ku, \\ Hiroshima 734-855 I, Japan; '2Department of Translational Cancer Research, Research Institute for Radiation Biology and Medicine, Hiroshima University, \\ Hiroshima, Japan
}

Telomeres, guanine-rich tandem DNA repeats of the chromosomal end, provide chromosomal stability, and cellular replication causes their loss. In somatic cells, the activity of telomerase, a reverse transcriptase that can elongate telomeric repeats, is usually diminished after birth so that the telomere length is gradually shortened with cell divisions, and triggers cellular senescence. In embryonic stem cells, telomerase is activated and maintains telomere length and cellular immortality; however, the level of telomerase activity is low or absent in the majority of stem cells regardless of their proliferative capacity. Thus, even in stem cells, except for embryonal stem cells and cancer stem cells, telomere shortening occurs during replicative ageing, possibly at a slower rate than that in normal somatic cells. Recently, the importance of telomere maintenance in human stem cells has been highlighted by studies on dyskeratosis congenital, which is a genetic disorder in the human telomerase component. The regulation of telomere length and telomerase activity is a complex and dynamic process that is tightly linked to cell cycle regulation in human stem cells. Here we review the role of telomeres and telomerase in the function and capacity of the human stem cells.

British Journal of Cancer (2007) 96, 1020- 1024. doi:I0.1038/sj.bjc.660367I www.bjcancer.com

Published online 13 March 2007

(C) 2007 Cancer Research UK

Keywords: telomere; telomerase; stem cell; cancer stem cell; dyskeratosis congenita

Telomere, a complex of guanine-rich repeat sequences and associated proteins, caps and protects every eukaryotic chromosome end against chromosomal fusion, recombination, and terminal DNA degradation (Blackburn, 2001). Telomeric DNA consists of short guanine-rich repeat sequences in all eukaryotes with linear chromosomes, and its length in human somatic cells is remarkably heterogeneous among individuals ranging from 5 to $20 \mathrm{~kb}$, according to age, organ, and the proliferative history of each cell (Wright and Shay, 2005). During a process of DNA synthesis and cell division, telomeres shorten as a result of the incomplete replication of linear chromosomes, the so-called 'end-replication problem'. This progressive telomere shortening is one of the molecular mechanisms underlying ageing, as critically short telomeres trigger chromosome senescence and loss of cell viability (Collins and Mitchell, 2002; Blasco, 2005; Wright and Shay, 2005). To prevent degradation by exonucleases or processing as damaged DNA, the telomere $3^{\prime}$ single-strand overhang folds back into the D-loop of duplex telomeric DNA to form a protective 'T-loop', which is reinforced with TRF2 and other telomeric DNA-binding proteins named Shelterin (de Lange, 2005).

Telomerase is a complex of a reverse transcriptase protein encoded by the TERT (telomerase reverse transcriptase) gene and a template RNA TERC (telomerase RNA component). Telomerase can add telomeric repeats onto the chromosome ends, and prevents the replication-dependent loss of telomere and cellular senescence in highly proliferative cells of the germline and

*Correspondence: Professor E Hiyama; E-mail: eiso@Hiroshima-u.ac.jp Received 24 October 2006; revised 6 February 2007; accepted 7 February 2007; published online 13 March 2007 in the majority of cancers (Blasco, 2005). Thus, telomerase a ctivity and telomere maintenance are associated with the immortality of cancer cells, germ-line cells, and embryonic stem (ES) cells.

In most human somatic cells except for stem cells and lymphocytes, telomerase activity is diminished after birth so that telomere length shortens with each cell division. A critical length of telomere repeats is required to ensure proper telomere function and avoid the activation of DNA damage pathways that result in replicative senescence or cell death. As stem cells have elongated proliferative capacity, they should have a mechanism that maintains telomere length through many cell divisions. In fact, low levels of telomerase activity have been found in human adult stem cells including haematopoietic and non-haematopoietic stem cells such as neuronal, skin, intestinal crypt, mammary epithelial, pancreas, adrenal cortex, kidney, and mesenchymal stem cells (MSCs) (Table 1). Basically, given the difference of telomere and telomerase activity in human and mouse cells, the telomere and telomerase status in stem cell populations is different between humans and mice (Harrington, 2004). The level of telomerase is low in the majority of human stem cells, whereas it is upregulated in cells that undergo rapid expansion, such as committed haematopoietic progenitor cells, activated lymphocytes, or keratinocytes, even within tissues with a low cell turnover such as the brain (Haik et al, 2000; Figure 1).

Mutations in telomerase core components, TERT and TERC, have been found in patients suffering from aplastic anaemia and dyskeratosis congenital (DKC), as described later. Both diseases are characterised by bone marrow failure and/or skin abnormalities, resulting from defects in maintaining the haematopoietic stem cell compartment. Moreover, cancer and ageing, two 
Table I Telomere and telomerase in human stem cells

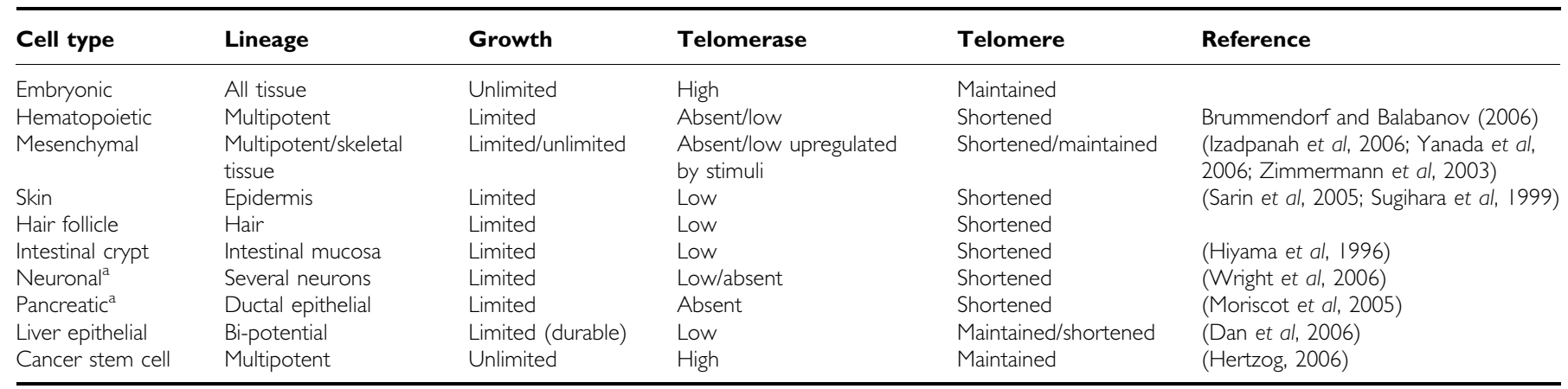

${ }^{a}$ These stem cells may be derived from hMSCs.

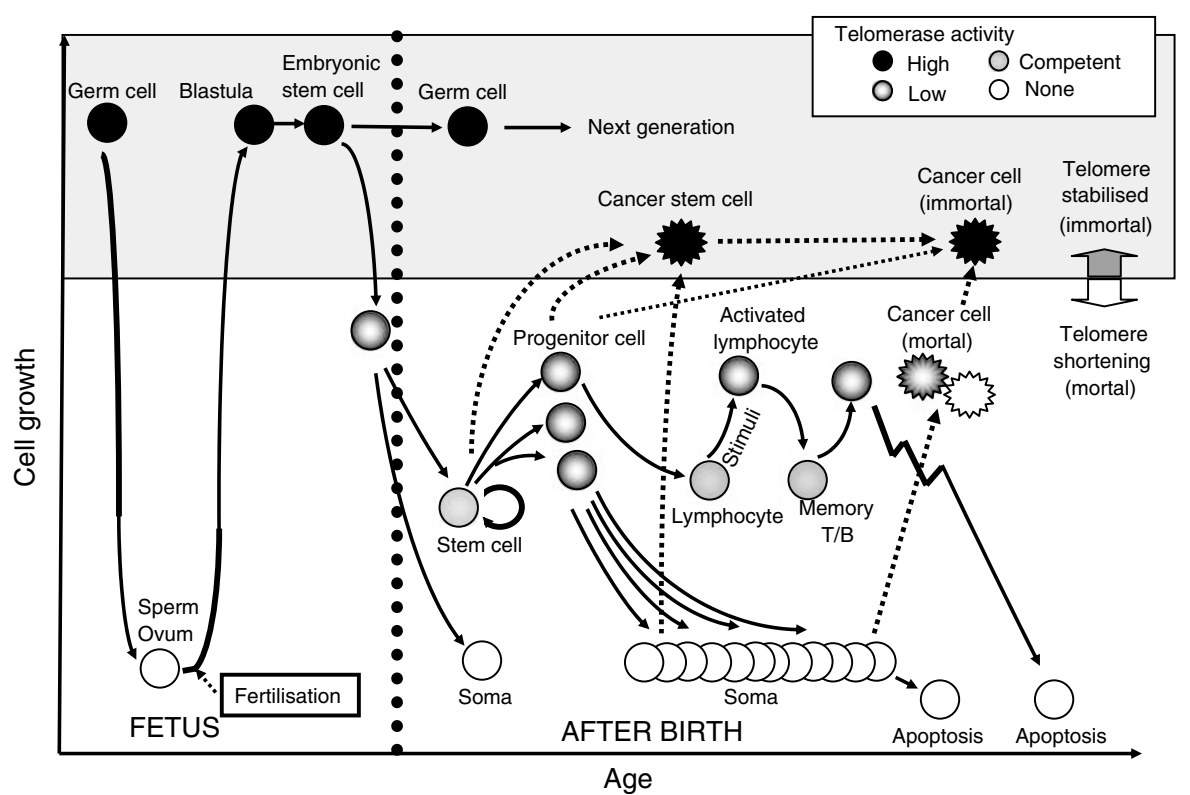

Figure I Telomere and telomerase dynamics in human stem cells. Germ cells have high levels of telomerase activity during rapid proliferation. Although telomerase activity is diminished in non-proliferating sperms and ova, it is highly activated after fertilisation and maintained in ES cells and germ cells for the next generation. In the developmental stage, telomerase activity gradually decreases and diminishes in most somatic cells after birth. In adult stem cells, the level of telomerase activity is low or undetectable, and upregulated in committed progenitor cells which have high reproducible activity in each tissue but insufficient to stably maintain their telomere length. Thus, normal stem cells are considered to be mortal and finally senesce by telomere shortening. Cancer stem cells can be derived from normal stem cells, progenitor cells, or possibly somatic cells and might be immortal, having the capacity of indefinite self-renewal and proliferation.

biological processes in which the role of telomerase has been implicated, are increasingly recognised as stem cell diseases. For example, some cancers may originate from the transformants of normal stem cells or progenitor cells, so-called cancer stem cells (CSCs), whereas ageing is induced through a progressive functional decline in certain stem cells (McEachern et al, 2000).

\section{TELOMERES AND TELOMERASE IN HAEMATOPOIETIC STEM CELLS}

In the haematopoietic system, telomerase-expressing cells are stem cells with self-renewal potential and their early descendants (Hiyama et al, 1995; Morrison et al, 1996). Age-dependent loss of telomeric DNA has been observed in both lymphocytes and neutrophils (Vaziri et al, 1993) as well as in other tissues (Hiyama et al, 1996; Wright and Shay, 2005). The length of telomeres in adult blood leucocytes was reported to be shorter than that in germline cells from the same donor (Cooke and Smith, 1986). A subset of stem cells isolated from adult bone marrow showed shorter telomeres than a similar subset isolated from fetal liver or cord blood, suggesting that a progressive decline in telomere length with age occurs in haematopoietic stem cells (HSCs) (Vaziri et al, 1993). It is possible that transplanted HSCs derived from aged donors may reach their proliferative limit during the lifetime of the recipient. In fact, several cases with graft failure after HSC transplant have been reported to have unusual telomere shortening (Wynn et al, 1998).

Low levels of telomerase activity are readily detectable in HSCs and in some of their differentiated progeny including peripheral blood lymphocytes (Hiyama et al, 1995; Morrison et al, 1996). Nevertheless, the age-related loss of telomeric DNA in these cells suggests that telomerase activity in HSCs is insufficient to completely prevent telomere loss. Telomere length alterations have also been noted in myelodysplastic syndromes (MDS) and chronic myeloid leukaemia (CML), where telomere loss in HSCs may be associated with cellular senescence and ineffective haematopoiesis as well as contributing to genomic instability and subsequent leukaemic progression (Ohyashiki et al, 2002). These data support the idea that replicative potential of HSCs could be 
limited by progressive telomere shortening and that telomere length can be used as an indirect indicator of stem cell proliferative history and potential. Bone marrow insufficiency in a telomerasedeficient disease, DKC (Vulliamy et al, 2001), may be further evidence of that.

Telomerase activity appears to be upregulated in response to cytokine-induced proliferation and cell cycle activation in primitive HSCs, and progressively downregulated in more matured subsets (Chiu et al, 1996) except for mitogenically activated lymphocytes (Hiyama et al, 1995) (Figure 1). Stem cells are capable of generating a very large number of committed progenitors and their descendants during a small number of self-renewal divisions. As such, individual stem cell turnover at any given point would be minimal and the upregulation of telomerase activity in stem cells could be minimal, preventing the generation of overly long telomeres (Collins and Mitchell, 2002). Transient activation of telomerase activity induced during periods of rapid cellular proliferation could reduce telomere loss in lineage-committed progenitor cells. In more mature cells, telomerase activity is repressed irrelevant to their proliferation. These findings suggest that one important function of telomerase in HSCs is to reduce the rate of telomere loss during the period of rapid cell division, preventing premature critical shortening of telomeres and loss of telomere function. Such a role of telomerase would be critically important in the case of increased proliferative demand, such as infection or blood loss (Allsopp et al, 2003).

\section{NON-HAEMATOPOIETIC STEM CELLS}

Some controversial data remain in telomerase activity and TERT expression in non-HSC (NHSCs). The difference of the levels of telomerase activity in NHSC components of various organs is likely derived from the difference of their cellular turnover among organs. In this review, as representative NHSCs, we focused on MSCs.

Stem cells for mesenchymal tissues, which can be derived from bone marrow, are commonly termed MSCs. Mesenchymal stem cells could differentiate into multiple mesoderm-type cell lineages (Prockop, 1997), such as fibroblasts, adipocytes, osteoblasts, chondrocytes, and endothelial cells, as well as into non-mesoderm-type lineages, such as neuronal-like cells. The phenotype of replicative senescence in cultured MSCs depends on the species. For instance, human MSCs (hMSCs) were reported to cease dividing rather early (around 40-50 population doublings), whereas murine MSCs (mMSCs), that have telomerase activity, could be passaged for more than 100 population doublings (Meirelles Lda and Nardi, 2003). Other investigators also reported for hMSCs that telomere length gradually shortened at a similar rate to non-stem cells $\left(30-120 \mathrm{bp} \mathrm{PD}^{-1}\right)$ and telomerase activity was undetectable (Fehrer and Lepperdinger, 2005). However, several growth factors enhance the mitotic potential of hMSC, and we recently found that bone marrow-derived hMSCs maintained long telomeres without the upregulation of telomerase activity for more than 100 population doublings under culture with basic FGF (Yanada et al, 2006). Moreover, forced telomerase expression in hMSCs led to an extended life span and enhanced differentiation potential (Simonsen et al, 2002). Even using highly sensitive assays, no telomerase activity has been detected in hMSCs so far, and there may be a mechanism of telomere maintenance other than telomerase, such as alternative lengthening of telomeres, in hMSCs. Recent observation of subtelomeric DNA hypomethylation facilitating telomere elongation in mammalian cells suggests that such epigenetic modification of chromatin may occur in hMSCs (Gonzalo et al, 2006). On the other hand, mMSCs with their telomerase activity knocked-down completely failed to differentiate into adipocytes or chondrocytes, even in early passages (Liu et al, 2004). Also in hMSCs, overexpression of telomerase indeed resulted in the elongation of telomeres, and TERT-transfected cells kept proliferating when untransfected control cells ceased growth. Furthermore, the potential of telomerase-overexpressing cells to form bone in vivo was greatly enhanced (Simonsen et al, 2002). Most likely, telomerase is required for both cell replication and differentiation. The latter implies that hMSCs may express at least the minimum level of telomerase activity to bring about regenerative capacity and differentiation potential.

In other NHSCs, it has been shown that hepatocytes become senescent owing to telomere shortening in the cirrhotic stage of a wide variety of chronic human liver diseases. Intriguingly, mesenchymal cell-like endothelial cells and hepatic satellite cells do not show this replicative senescence (Dan et al, 2006). The replicative senescence in hepatocytes is probably in part the result of continued proliferation during 20-30 years of chronic liver diseases. Chronic inflammation, the presence of growth factors, and DNA-damaging agents such as reactive oxygen and nitrogen species may also play a role in this process.

\section{DISEASES DUE TO LACK OF TELOMERASE IN STEM CELLS: DKC AND APLASTIC ANAEMIA}

The critical importance of telomerase activity in human stem cells has been recently highlighted as the aetiology of DKC. In this disease, a defect of the telomerase RNA template gene results in the absence of telomerase activity and premature telomere shortening, developing bone marrow failure, intestinal disorder, or malignancy, typically under 50 years old. Positional cloning identified the gene affected in many patients with X-linked DKC as the human homologue of yeast CBF5, termed $D K C 1$, encoding a protein, dyskerin. The association of the telomerase complex with dyskerin suggested that the DKC phenotype may be the result of altered telomerase activity (Vulliamy et al, 2001). Then, the discovery of a $3^{\prime}$ deletion in the gene encoding TERC in a single large family with autosomal dominant DKC confirmed the importance of telomerase deficiency as the aetiology for DKC and highlighted the importance of telomerase in maintaining cellular lifespan and replicative potential in human organs. As mice have much longer telomeres that cannot be seriously shortened within their short lifetime, this situation contrasts markedly with Terc knockout mice where completely absent telomerase activity is tolerated without abnormality in the first few generations. After the fourth generation, Terc knockout mice begin to exhibit abnormalities similar to the phenotype of human DKC (Samper et al, 2002). Wild-type mice derived from late generations of Terc $+I-$ mice with short telomeres and positive telomerase activity displayed a similar phonotype of DKC, indicating that short telomeres themselves, rather than lack of telomerase activity, cause stem cell failure (Hao et al, 2005). Recently, Cdkn1a deletion improved stem cell function and lifespan of mice with telomere dysfunction, indicating that upregulation of p21 (encoded by $C d k n 1 a)$ in response to shortened telomeres impairs repopulation capacity of stem cells in age-related diseases and senescence (Choudhury et al, 2007).

Aplastic anaemia results from the failure of bone marrow to produce sufficient quantities of all haematopoietic lineages. The aetiology of this disease is unclear in most cases, but is generally thought to be the result of HSC damage or loss. Telomere length in peripheral blood granulocytes and monocytes in patients with aplastic anaemia or related disorders was significantly shorter than that in age-matched controls, and correlated with disease duration (Lee et al, 2001). An inverse correlation between age-adjusted telomere length and peripheral blood counts was also observed in aplastic anaemia (Brummendorf et al, 2001). As in DKC-associated aplastic anaemia, a report found mutations in the TERC gene in patients with aplastic anaemia (Vulliamy et al, 2002). Data from 
congenital disorders, like DKC and aplastic anaemia, suggest that disturbed telomere maintenance may play a role in replicative exhaustion of the HSC pool in vivo, which might be correlated with age-related diseases and senescence.

\section{EMBRYONIC STEM CELLS}

Embryonic stem cells, more primitive stem cells, are likely to be potentially immortal and capable of indefinite self-renewal together with the ability to differentiate and contribute to the germ line. Embryonic stem cells and undifferentiated embryonal carcinoma (EC) cells display high levels of telomerase activity and hTERT expression, both of which are rapidly downregulated during differentiation (Armstrong et al, 2005) and much lower or absent in somatic cells including stem cells in self-renewal tissues (Figure 1). The downregulation of telomerase activity in differentiating EC cells was reported to be tightly correlated with histone deacetylation and DNA methylation of the TERT gene (Lopatina et al, 2003). Moreover, increased telomerase activity enhanced selfrenewal ability, proliferation, and differentiation efficiency in Tertoverexpressing ES cells (Armstrong et al, 2005). High telomerase activity or the expression of TERT can therefore be regarded as a marker of undifferentiated ES cells.

In cloned animals originating from adult nuclei with shortened telomeres, telomere length in somatic cells has been found to be comparable with that in age-matched normal animals originating from a fertilised egg with long telomeres. This finding indicates that the enucleated oocyte has the ability to reset the telomere length of the nucleus derived from a donor adult somatic cell by the elongation of telomeres (Meerdo et al, 2005). Elucidation of this 'reset' mechanism in oocytes will be a technical breakthrough in developing cloned animals.

\section{CANCER STEM CELLS}

The first evidence that a rare population of stem cells maintain the human cancer came from a study on haematopoietic malignancies (Lapidot et al, 1994). Haematopoietic malignancies can be divided into premalignant, chronic, and acute stages, the last being the most advanced and malignant. It is known that the premalignant stage, such as MDS, and the chronic stage, such as CML or chronic lymphoid leukaemia, can progress into a more malignant and acute stage of the disease, for example, acute lymphoid or myeloid leukaemia (Greenberg et al, 1997). In this progression, telomere shortening in HSCs is considered to be a risk factor that contributes to the development of chromosomal instability and malignant transformation. In agreement with this hypothesis, telomere shortening in patients with DKC correlates with an increased risk of haematological neoplasia (Mason et al, 2005). Similar to haematopoietic malignancies, several kinds of solid cancers, especially breast and brain cancers (Singh et al, 2003; Al-Hajj and Clarke, 2004), are considered to be generated and/or propagated by CSCs.

To maintain their characteristic replicative ability, CSCs should have telomere-lengthening mechanisms; however, since the identification and purification of CSCs are difficult in most solid tumors, the telomere and telomerase dynamics in CSCs remain unclear. Regardless of the derivation of CSCs, normal stem cells, committed progenitor cells, or differentiated cells (Clarke and Fuller, 2006), CSCs might have acquired immortality by mutational events in telomere-lengthening mechanisms, typically the activation of telomerase (Ohyashiki et al, 2002), considering that telomere shortening and cellular senescence are inevitable in these original cells (Figure 1), except for some MSCs. Theoretically, the inhibition of telomerase in CSCs to limit proliferation capacity and induce apoptosis, the stabilisation of telomeres in premalignant lesions to prevent the activation of telomerase and transformation to CSCs, and the identification of specific marker proteins in CSCs in each organ are likely to optimise screening and therapeutic interventions as novel anticancer strategies.

\section{CONCLUSIONS}

Recent research has focused on telomeres and their role in cell cycle regulation, cellular senescence, and genetic instability; however, much remains to be learned, and what is clear is the complexity of telomere and telomerase interactions in cell cycle progression and cell signaling in both normal somatic cells and malignant cells. Both elements have a key role in determining proliferative capacity in all human cells. Telomere shortening occurs in most human somatic cells and triggers DNA damage responses that mediate cell cycle arrest or apoptosis, while HSCs can escape this trigger by employing a telomerase-dependent telomere lengthening mechanism in replication. This process in normal HSCs, however, appears to have only limited potential in extending the replicative capacity, because the telomere shortening occurs slowly but steadily in blood cells with ageing. In contrast, CSCs should have complete telomere-lengthening mechanisms that provide indefinite proliferation capacity. Research on telomeretelomerase dynamics in stem cells could lead to the development of novel aetiology-based radical therapies in ageing-related diseases and cancers.

\section{REFERENCES}

Al-Hajj M, Clarke MF (2004) Self-renewal and solid tumor stem cells. Oncogene 23: 7274-7282

Allsopp RC, Morin GB, DePinho R, Harley CB, Weissman IL (2003) Telomerase is required to slow telomere shortening and extend replicative lifespan of HSCs during serial transplantation. Blood 102: $517-520$

Armstrong L, Saretzki G, Peters H, Wappler I, Evans J, Hole N, von Zglinicki T, Lako M (2005) Overexpression of telomerase confers growth advantage, stress resistance, and enhanced differentiation of ESCs toward the hematopoietic lineage. Stem Cells 23: 516-529

Blackburn EH (2001) Switching and signaling at the telomere. Cell 106: $661-673$

Blasco MA (2005) Telomeres and human disease: ageing, cancer and beyond. Nat Rev Genet 6: 611-622

Brummendorf TH, Balabanov S (2006) Telomere length dynamics in normal hematopoiesis and in disease states characterized by increased stem cell turnover. Leukemia 29: 273-275
Brummendorf TH, Maciejewski JP, Mak J, Young NS, Lansdorp PM (2001) Telomere length in leukocyte subpopulations of patients with aplastic anemia. Blood 97: 895-900

Chiu CP, Dragowska W, Kim NW, Vaziri H, Yui J, Thomas TE, Harley CB, Lansdorp PM (1996) Differential expression of telomerase activity in hematopoietic progenitors from adult human bone marrow. Stem Cells 14: $239-248$

Choudhury AR, Ju Z, Djojosubroto MW, Schienke A, Lechel A, Schaetzlein S, Jiang H, Stepczynska A, Wang C, Buer J, Lee HW, von Zglinicki T, Ganser A, Schirmacher P, Nakauchi H, Rudolph KL (2007) Cdknla deletion improves stem cell function and lifespan of mice with dysfunctional telomeres without accelerating cancer formation. Nat Genet 39: 99-105

Clarke MF, Fuller M (2006) Stem cells and cancer: two faces of eve. Cell 124: $1111-1115$

Collins K, Mitchell JR (2002) Telomerase in the human organism. Oncogene 21: $564-579$ 
Cooke HJ, Smith BA (1986) Variability at the telomeres of the human X/Y pseudoautosomal region. Cold Spring Harb Symp Quant Biol 51(Part 1): $213-219$

Dan YY, Riehle KJ, Lazaro C, Teoh N, Haque J, Campbell JS, Fausto N (2006) Isolation of multipotent progenitor cells from human fetal liver capable of differentiating into liver and mesenchymal lineages. Proc Natl Acad Sci USA 103: $9912-9917$

de Lange $T$ (2005) Shelterin: the protein complex that shapes and safeguards human telomeres. Genes Dev 19: 2100-2110

Fehrer C, Lepperdinger G (2005) Mesenchymal stem cell aging. Exp Gerontol 40: 926 -930

Gonzalo S, Jaco I, Fraga MF, Chen T, Li E, Esteller M, Blasco MA (2006) DNA methyltransferases control telomere length and telomere recombination in mammalian cells. Nat Cell Biol 8: 416-424

Greenberg P, Cox C, LeBeau MM, Fenaux P, Morel P, Sanz G, Sanz M, Vallespi T, Hamblin T, Oscier D, Ohyashiki K, Toyama K, Aul C, Mufti G, Bennett J (1997) International scoring system for evaluating prognosis in myelodysplastic syndromes. Blood 89: 2079-2088

Haik S, Gauthier LR, Granotier C, Peyrin JM, Lages CS, Dormont D, Boussin FD (2000) Fibroblast growth factor 2 up regulates telomerase activity in neural precursor cells. Oncogene 19: 2957-2966

Hao LY, Armanios M, Strong MA, Karim B, Feldser DM, Huso D, Greider CW (2005) Short telomeres, even in the presence of telomerase, limit tissue renewal capacity. Cell 123: $1121-1131$

Harrington L (2004) Does the reservoir for self-renewal stem from the ends? Oncogene 23: $7283-7289$

Hertzog RG (2006) Ancestral telomere shortening: a countdown that will increase mean life span? Med Hypotheses 67: 157-160

Hiyama E, Hiyama K, Tatsumoto N, Kodama T, Shay JW, Yokoyama T (1996) Telomerase activity in human intestine. Int I Oncol 9: 453-458

Hiyama K, Hirai Y, Kyoizumi S, Akiyama M, Hiyama E, Piatyszek MA, Shay JW (1995) Activation of telomerase in human lymphocytes and hematopoietic progenitor cells. J Immunol 155: 3711 - 3715

Izadpanah R, Trygg C, Patel B, Kriedt C, Dufour J, Gimble JM, Bunnell BA (2006) Biologic properties of mesenchymal stem cells derived from bone marrow and adipose tissue. J Cell Biochem 99: 1285-1297

Lapidot T, Sirard C, Vormoor J, Murdoch B, Hoang T, Caceres-Cortes J, Minden M, Paterson B, Caligiuri MA, Dick JE (1994) A cell initiating human acute myeloid leukaemia after transplantation into SCID mice. Nature 367: 645-648

Lee JJ, Kook H, Chung IJ, Na JA, Park MR, Hwang TJ, Kwak JY, Sohn SK, Kim HJ (2001) Telomere length changes in patients with aplastic anaemia. Br J Haematol 112: $1025-1030$

Liu L, DiGirolamo CM, Navarro PA, Blasco MA, Keefe DL (2004) Telomerase deficiency impairs differentiation of mesenchymal stem cells. Exp Cell Res 294: $1-8$

Lopatina NG, Poole JC, Saldanha SN, Hansen NJ, Key JS, Pita MA, Andrews LG, Tollefsbol TO (2003) Control mechanisms in the regulation of telomerase reverse transcriptase expression in differentiating human teratocarcinoma cells. Biochem Biophys Res Commun 306: 650-659

Mason PJ, Wilson DB, Bessler M (2005) Dyskeratosis congenita - a disease of dysfunctional telomere maintenance. Curr Mol Med 5: 159-170

McEachern MJ, Krauskopf A, Blackburn EH (2000) Telomeres and their control. Annu Rev Genet 34: $331-358$

Meerdo LN, Reed WA, White KL (2005) Telomere-to-centromere ratio of bovine clones, embryos, gametes, fetal cells, and adult cells. Cloning Stem Cells 7: $62-73$
Meirelles Lda S, Nardi NB (2003) Murine marrow-derived mesenchymal stem cell: isolation, in vitro expansion, and characterization. $\mathrm{Br} J$ Haematol 123: $702-711$

Moriscot C, de Fraipont F, Richard MJ, Marchand M, Savatier P, Bosco D, Favrot M, Benhamou PY (2005) Human bone marrow mesenchymal stem cells can express insulin and key transcription factors of the endocrine pancreas developmental pathway upon genetic and/or microenvironmental manipulation in vitro. Stem Cells 23: 594-603

Morrison SJ, Prowse KR, Ho P, Weissman IL (1996) Telomerase activity in hematopoietic cells is associated with self-renewal potential. Immunity 5 : $207-216$

Ohyashiki JH, Sashida G, Tauchi T, Ohyashiki K (2002) Telomeres and telomerase in hematologic neoplasia. Oncogene 21: 680-687

Prockop DJ (1997) Marrow stromal cells as stem cells for nonhematopoietic tissues. Science 276: $71-74$

Samper E, Fernandez P, Eguia R, Martin-Rivera L, Bernad A, Blasco MA, Aracil M (2002) Long-term repopulating ability of telomerase-deficient murine hematopoietic stem cells. Blood 99: 2767-2775

Sarin KY, Cheung P, Gilison D, Lee E, Tennen RI, Wang E, Artandi MK, Oro AE, Artandi SE (2005) Conditional telomerase induction causes proliferation of hair follicle stem cells. Nature 436: $1048-1052$

Simonsen JL, Rosada C, Serakinci N, Justesen J, Stenderup K, Rattan SI, Jensen TG, Kassem M (2002) Telomerase expression extends the proliferative life-span and maintains the osteogenic potential of human bone marrow stromal cells. Nat Biotechnol 20: 592-596

Singh SK, Clarke ID, Terasaki M, Bonn VE, Hawkins C, Squire J, Dirks PB (2003) Identification of a cancer stem cell in human brain tumors. Cancer Res 63: 5821-5828

Sugihara M, Ohshima K, Nakamura H, Suzumiya J, Nakayama Y, Kanda M, Haraoka S, Kikuchi M (1999) Decreased expression of telomeraseassociated RNAs in the proliferation of stem cells in comparison with continuous expression in malignant tumors. Int J Oncol 15: 1075-1080

Vaziri H, Schachter F, Uchida I, Wei L, Zhu X, Effros R, Cohen D, Harley CB (1993) Loss of telomeric DNA during aging of normal and trisomy 21 human lymphocytes. Am J Hum Genet 52: $661-667$

Vulliamy T, Marrone A, Dokal I, Mason PJ (2002) Association between aplastic anaemia and mutations in telomerase RNA. Lancet 359: $2168-2170$

Vulliamy T, Marrone A, Goldman F, Dearlove A, Bessler M, Mason PJ, Dokal I (2001) The RNA component of telomerase is mutated in autosomal dominant dyskeratosis congenita. Nature 413: $432-435$

Wright LS, Prowse KR, Wallace K, Linskens MH, Svendsen CN (2006) Human progenitor cells isolated from the developing cortex undergo decreased neurogenesis and eventual senescence following expansion in vitro. Exp Cell Res 312: $2107-2120$

Wright WE, Shay JW (2005) Telomere biology in aging and cancer. J Am Geriatr Soc 53: S292-S294

Wynn RF, Cross MA, Hatton C, Will AM, Lashford LS, Dexter TM, Testa NG (1998) Accelerated telomere shortening in young recipients of allogeneic bone-marrow transplants. Lancet 351: 178-181

Yanada S, Ochi M, Kojima K, Sharman P, Yasunaga Y, Hiyama E (2006) Possibility of selection of chondrogenic progenitor cells by telomere length in FGF-2-expanded mesenchymal stromal cells. Cell Prolif 39: $575-584$

Zimmermann S, Voss M, Kaiser S, Kapp U, Waller CF, Martens UM (2003) Lack of telomerase activity in human mesenchymal stem cells. Leukemia 17: $1146-1149$ 